\title{
Clinical Significance of the Histoculture Drug Response Assay in Breast Cancer
}

\author{
YOSHIAKI SHINDEN, YUKO KIJIMA, MUNETSUGU HIRATA, HIDEO ARIMA, \\ AKIHIRO NAKAJYO, KIYONORI TANOUE, KOSEI MAEMURA and SHOJI NATSUGOE \\ Department of Digestive Surgery, Breast and Thyroid Surgery, \\ Kagoshima University Graduate School of Medical and Dental Sciences, Kagoshima, Japan
}

\begin{abstract}
Background/Aim: Despite the fact that breast cancer patients are generally administered systemic chemotherapy after surgical treatment, predictive factors that allow optimization of chemotherapy are needed. The histoculture drug response assay (HDRA) is a clinically practical in vitro drug-response assay for identifying optimal anticancer agents. Patients and Methods: Thirty-eight primary breast cancer patients who underwent surgical treatment without receiving systemic neoadjuvant therapy were analyzed. We retrospectively examined the relationships between clinicopathological factors and the HDRA results of 5 anticancer agents (mitomycin C (MMC), 5-fluorouracil (5$F U)$, doxorubicin hydrochloride (ADM), cisplatin (CDDP) and paclitaxel (PTX)). Results: The relationships between the inhibition rates of anticancer drugs and clinicopathological factors were not significant, except for nuclear grade and venous invasion with the inhibition rate of 5-FU. We also established the threshold inhibition rate for PTX. The paclitaxel inhibition rate was significantly associated with disease-free survival (DFS). Conclusion: HDRA results were independent from the clinicopathological factors of breast cancer patients demonstrating that individualized treatment is needed.
\end{abstract}

Breast cancer is the most common cancer in women worldwide. Postoperative adjuvant chemotherapy is widely used for the treatment of breast cancer. Nowadays, systemic

This article is freely accessible online.

Correspondence to: Yuko Kijima, MD, Ph.D., Department of Digestive Surgery, Breast and Thyroid Surgery, Kagoshima University Graduate School of Medical and Dental Sciences, 8-351, Sakuragaoka, Kagoshima 890-8520, Japan. Tel: +81 992755361, Fax: +81 992657426, e-mail: ykijima@m3.kufm.kagoshima-u.ac.jp

Key Words: Histoculture drug response assay, breast cancer, clinicopathological factors. chemotherapy for breast cancer generally includes anthracyclines and/or taxanes and/or the antimetabolite 5fluorouracil (5-FU), which are the most active cytotoxic agents for both early and advanced breast cancer (1). Although anthracyclines have been shown to provide increased benefits for breast cancer patients with HER2 overexpression compared to patients without HER2 overexpression (2), other clinicopathological breast cancer markers that might allow the optimization of chemotherapy remain unverified.

The histoculture drug response assay (HDRA) was developed as an in vitro drug-response assay for choosing anticancer agents (3). The tumor inhibition rates (IRs) of chemotherapy agents evaluated by the HDRA were found to be predictive of response of various types of cancer to chemotherapy (4-8). However, the relationships between the clinicopathological factors of tumors and HDRA IRs of chemotherapy agents have not been clarified.

Herein, we report an investigation of HDRA used for primary breast cancer tumors, which included an analysis of the relationship between the clinicopathological characteristics of tumors and their in vitro response to chemotherapy agents.

\section{Patients and Methods}

Patients. Thirty-eight patients with primary breast cancer who underwent surgical treatment without receiving neoadjuvant therapy at Kagoshima University Hospital, Kagoshima, Japan, were enrolled in this study. Diagnosis of breast cancer was performed on a core needle biopsy (CNB) specimen from each patient. After histopathological diagnosis of hematoxyline-and-eosin-stained CNB sections, followed by immunohistochemical staining for estrogen receptor (ER), progesterone receptor (PgR), HER2 and Ki67 (9), the tumors were classified into the following 4 subtypes: luminal A, luminal B, HER2-enriched and triple-negative (TN). From June 2011 to March 2014, only TN specimens were included and from April 2014 to August 2015, all subtypes were included. Patients with an excised tumor with insufficient tissue for the HDRA were excluded. Adjuvant therapy was selected for each patient based on the National Comprehensive Cancer Network guidelines (10). Demographic data of the patients, clinicopathological features of the 
Table I. Clinicopathological characteristics of patients.

\begin{tabular}{|c|c|}
\hline Factors & Number \\
\hline Total number of patients & 38 \\
\hline Median age (years) & 62 \\
\hline Median follow-up duration (months) & 12 \\
\hline \multicolumn{2}{|l|}{ Estrogen receptor } \\
\hline Positive & 19 \\
\hline Negative & 19 \\
\hline \multicolumn{2}{|l|}{ Progestrone receptor } \\
\hline Positive & 16 \\
\hline Negative & 22 \\
\hline \multicolumn{2}{|l|}{ HER2 } \\
\hline Positive & 2 \\
\hline Negative & 36 \\
\hline \multicolumn{2}{|l|}{ Subtype* } \\
\hline Luminal A & 7 \\
\hline Luminal B & 10 \\
\hline Luminal HER2 & 2 \\
\hline HER2 enriched & 0 \\
\hline Triple negative & 19 \\
\hline \multicolumn{2}{|l|}{$\mathrm{T}$ factors $* *$} \\
\hline $\mathrm{T} 1-2$ & 26 \\
\hline $\mathrm{T} 3-4$ & 12 \\
\hline \multicolumn{2}{|l|}{ Lymph node metastasis } \\
\hline Absent & 17 \\
\hline Present & 21 \\
\hline \multicolumn{2}{|l|}{ Nuclear Grade } \\
\hline $1-2$ & 21 \\
\hline 3 & 16 \\
\hline Not available & 1 \\
\hline \multicolumn{2}{|l|}{ Lymphatic invasion } \\
\hline Absent & 10 \\
\hline Present & 28 \\
\hline \multicolumn{2}{|l|}{ Venous invasion } \\
\hline Absent & 34 \\
\hline Present & 4 \\
\hline \multicolumn{2}{|l|}{ Stage** } \\
\hline Stage I-II & 21 \\
\hline Stage III-IV & 17 \\
\hline \multicolumn{2}{|l|}{ Adjuvant systemic therapy } \\
\hline Chemotherapy & 11 \\
\hline Anthracycline & (3) \\
\hline Taxane & (1) \\
\hline Anthracycline + Taxane & (6) \\
\hline Fluorouracil & (1) \\
\hline Chemotherapy + Endocrine therapy & 6 \\
\hline Anthracycline & $(0)$ \\
\hline Taxane & (3) \\
\hline Anthracycline + Taxane & (3) \\
\hline Endocrine therapy & 11 \\
\hline No systemic therapy & 10 \\
\hline Reccurrence & 7 \\
\hline Cancer death & 2 \\
\hline
\end{tabular}

* Subtypes were classified accroding to the St. Gallen International Expert Consensus (7). The cut-off of Ki-67 was set at $20 \%$. **Clinical stage was assessed using TNM classification of malignant tumors, 7 th edition (13).

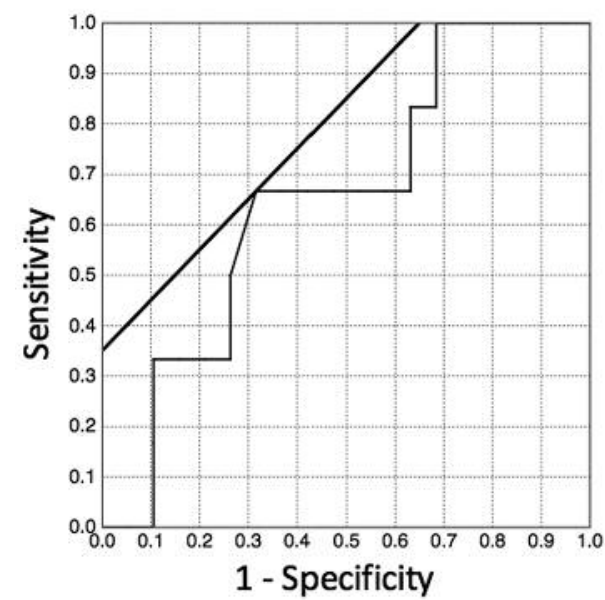

Figure 1. Receiver operating characteristic curve analysis of tumor inhibition rates associated with paclitaxel in relation to predicting the recurrence of breast cancer after treatment.

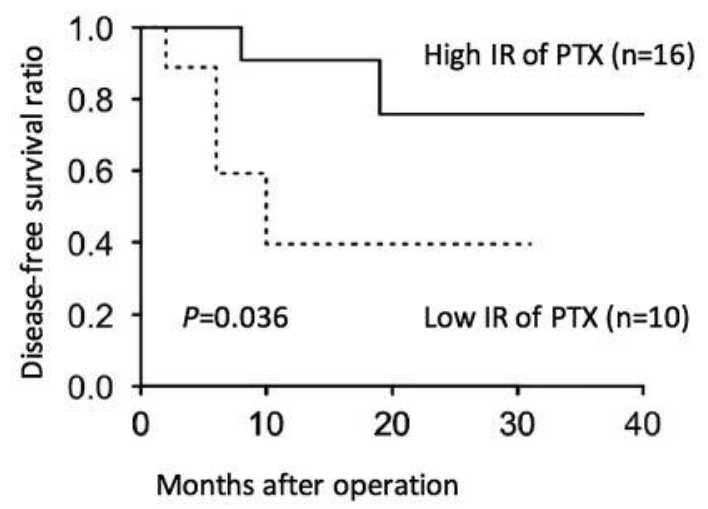

Figure 2. Kaplan-Meier disease-free survival curves of patients with breast cancer whose tumors showed high vs. low inhibition rates associated with paclitaxel.

tumors and other relevant data are shown in Table I. Each patient provided written informed consent before sample acquisition; this study was approved by the Institutional Review Board of Kagoshima University Hospital.

HDRA. Samples were immediately collected from resected primary tumors and cut into 5-mm cubes. The HDRA was performed by SRL Inc. (Tokyo, Japan). The HDRA procedures have been reported previously $(6,9)$. Briefly, pieces of tumor tissue, approximately $10 \mathrm{mg}$ each, were placed on a collagen sponge gel. They were incubated for 7 days with 5 anticancer agents (mitomycin C (MMC), 5-fluorouracil (5-FU), doxorubicin hydrochloride (ADM), cisplatin (CDDP) and paclitaxel (PTX)) in RPMI 1640 medium containing 20\% fetal calf serum at $37^{\circ} \mathrm{C}$ in a $5 \% \quad \mathrm{CO}_{2}$ atmosphere. Collagenase, 3-(4,5dimethylthiazol-2-yl)-2,5-diphenyltetrazolium bromide and $\mathrm{Na}$ 
a

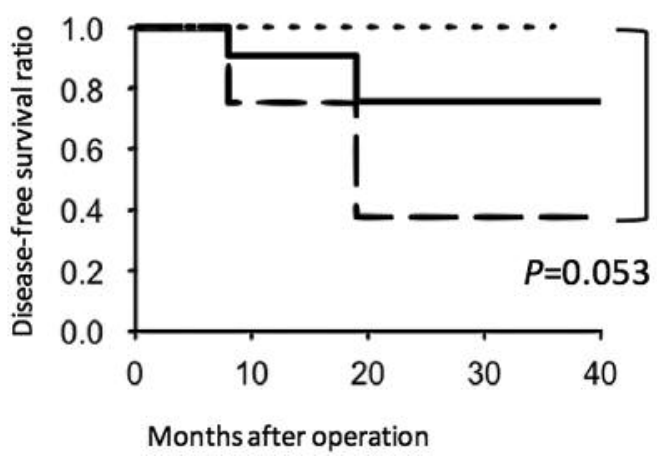

b

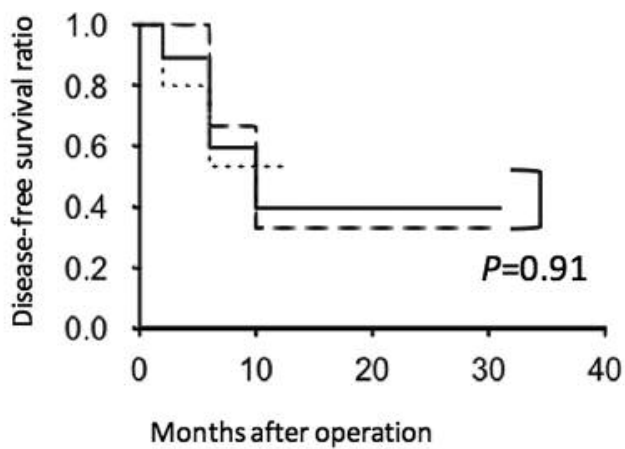

Figure 3. Kaplan-Meier disease-free survival curves of patients with breast cancer based on whether or not they received a taxane regimen. (a) Patients whose tumors showed high inhibition rates associated with paclitaxel (PTX) are shown by a solid line. Patients who received taxane (dashed line) or did not receive taxane (dotted line) were compared. (b) Patients whose tumors showed low IRs associated with PTX are shown by a solid line. Patients who received taxane (dashed line) or did not receive taxane (dotted line) were compared.

succinate were then added to the cultures that were incubated for an additional $16-\mathrm{h}$ period. The resulting formazan crystals were extracted from the tumor cultures by dimethyl sulfoxide. The optical density of each culture was measured at $540 \mathrm{~nm}$. The IR was calculated as (1-mean absorbance of treated tumor per $1 \mathrm{~g} /$ mean absorbance of untreated control tumor per $1 \mathrm{~g}) \times 100$. The IR cut-off values, as previously determined by SRL Inc., have been based on the histological response rates of each drug in breast cancer tumors (11). According to the predetermined threshold values for MMC (70\%), $\mathrm{ADM}(60 \%), 5 \mathrm{FU}(60 \%)$ and $\mathrm{CDDP}(50 \%)$, the breast cancer patients were divided into groups according to the IR values for each agent. Clinicopathological factors of the patients with high and low IR values for each agent were compared. Since the cut-off value of IR had never been determined for PTX, a receiver operating characteristic (ROC) curve of PTX IRs was plotted to predict recurrence and establish the missing cut-off value.

Statistical analysis. Differences in the clinicopathological factors between the groups were evaluated using analysis of variance for continuous variables and the Pearson Chi-square test for categorical variables. Disease-free survival (DFS) and overall survival (OS) were measured from the time of the first surgery until the date of death or last follow-up. Survival curves were constructed using the Kaplan-Meier method and statistical significance between groups was assessed using the log-rank test. Multivariate analysis was conducted using the Cox proportional hazards model. Statistical analysis was performed by JMP Pro Version 12.1.0 for Mac OS (SAS Institute Japan, Tokyo, Japan). $p$-Values less than 0.05 were considered statistically significant.

\section{Results}

Prognostic analysis based on PTX inhibition rates. To determine the cut-off value for the IR of PTX, we analyzed DFS and OS according to the IRs of PTX. To predict recurrence, the ROC curve of PTX IRs was analyzed and a cut-off value of $84 \%$ was established (Figure 1). Patients whose tumors had high PTX IR values had significantly longer DFS than the patients with low PTX IR values (Figure 2 ). The difference between the OS rates of the patients with high vs. low IRs for PTX was not significant (data not shown). Another analysis found no significant difference between the DFS rates of patients receiving PTX $v s$. those not receiving PTX (Figure 3). There was no significant difference between the DFS and OS rates of patients with high $v s$. low IRs for MMC, 5-FU, ADM and CDDP (data not shown). Multivariate analysis, using the Cox proportional hazards model, revealed that the PTX IR was an independent prognostic predictor for DFS (relative risk $(\mathrm{RR})=0.0097 ; 95 \%$ confidence interval $(\mathrm{CI})=0.0038-0.87 ; p=0.0036$ ) (Table II). Pathological $\mathrm{N}$ and nuclear grade were also found to be independent prognostic predictors $(\mathrm{RR}=16 ; 95 \% \mathrm{CI}=1.3-660 ; p=0.03$ and $\mathrm{RR}=14$; $95 \% \mathrm{CI}=1.4-420 ; p=0.025$, respectively).

Relationship between clinicopathological factors and tumorchemotherapy inhibition rates in the HDRA. The clinicopathological factors of patients and tumors classified based on high and low IR of the 5 anticancer agents (with the IR cut-off value of PTX as determined by us) are shown in Table III. The differences in the number of patients treated with 5-FU with high $v s$. low IR were significant for nuclear grade $(p=0.018)$ and venous invasion $(p=0.030)$. ER, PgR and HER2 positivity of tumors with high $v s$. low IR were not significant for any of the 5 agents.

\section{Discussion}

There are many clinicopathological factors that may predict the risk of postoperative recurrence in breast cancer; thus, the identification of risk factors is considered important for 
Table II. Results of the multivariate analysis of clinicopathological factors and disease-free survival (Cox proportional hazards model).

\begin{tabular}{|c|c|c|c|}
\hline Factors & $\begin{array}{c}\text { Univariate } \\
p \text {-Value }\end{array}$ & $\begin{array}{c}\text { Multivariate } \\
p \text {-Value }\end{array}$ & Relative Risk (95\% CI) \\
\hline $\mathrm{T}$ factor (Tis-2/T3-4) & 0.9 & & \\
\hline $\mathrm{N}$ factor (N0/N1-3) & 0.01 & 0.03 & $16(1.3-660)$ \\
\hline Nuclear Grade $(1-2 / 3)$ & 0.21 & 0.025 & $14(1.4-420)$ \\
\hline $\mathrm{Ki}-67(\leq 20 \% /<20 \%)$ & 0.85 & & \\
\hline ER (positive/negative) & 0.54 & & \\
\hline PgR (positive/negative) & 0.45 & & \\
\hline \multicolumn{4}{|l|}{ Chemotherapy $(+/-)$} \\
\hline All regimen $(+/-)$ & 0.17 & 0.12 & $6.2(0.66-200)$ \\
\hline PTX regimen $(+/-)$ & 0.34 & & \\
\hline Endocrine therapy $(+/-)$ & 0.76 & & \\
\hline PTX Inhibition rate (low/high) & 0.06 & 0.036 & $0.097(0.0038-0.87)$ \\
\hline
\end{tabular}

CI, Confidence interval; PTX, paclitaxel; ER, estrogen receptor; PgR; progesterone receptor.

deciding if systemic therapy is appropriate for a patient (12). However, the clinicopathological factors that are predictive of the efficacy of systemic chemotherapy have not been adequately clarified. Although HDRA is the only clinically practical method for estimating the efficacy of a specific chemotherapeutic agent, the relationships between clinicopathological factors, patient outcome and the data from HDRA are not completely understood. Thus, we analyzed the relationships between the tumor-chemotherapy IRs as assessed by HDRA and the clinicopathological factors of patients with primary breast cancer. There was a significant relationship between high nuclear grade and/or aggressive venous invasion of tumors with high IRs in response to 5-FU, which may indicate that highly aggressive tumors are sensitive to chemotherapy. High-grade breast cancers have been reported to be highly sensitive to cytotoxic chemotherapy, including 5FU regimens, in the setting of neoadjuvant chemotherapy (13). ER, PgR, HER2 and Ki-67 expression was not significantly different between the patients whose tumors had high vs. low IR to any of the drugs. These findings are consistent with a previous study by Kim et al. who did not find a significant relationship between drug sensitivity as determined by HDRA and subtypes of breast cancer (14).

In this study, we established a cut-off IR value for PTX of $84 \%$, since there was no previously determined value. Patients whose tumors showed high IRs to PTX had good DFS, with the PTX IR being significantly associated with DFS by multivariate analysis (Table III). However, none of the cut-off IR values of the 4 other anticancer drugs were found to be significantly associated with DFS. The significant association between the tumors with high PTX IRs and DFS might partially account for the effectiveness of taxane regimens. The effectiveness of taxanes against breast cancer has been reported by in vitro and neoadjuvant studies. Higher nuclear grade (15), higher Ki-67 values (16), younger age
(17) and TN subtypes (18) have been reported to be significant factors in patients with tumors that were highly sensitive to taxanes. We could not find any significant association between these factors and tumor IRs in relation to PTX. In our study, the chemotherapy regimens were not chosen based on HDRA results but on other clinicopathological factors. Only 5 out of 16 patients with tumors showing a high PTX IR received taxane-based chemotherapy. Although postoperative chemotherapy was only administered to patients considered to have poor prognosis, the presence or absence of chemotherapy using PTX was not found to be significantly associated with DFS by multivariate analysis. In addition, we did not find a significant difference in DFS associated with whether or not the patient received PTX (Figure 3). The predictive power of the PTX IR, as determined by HDRA, might have been influenced by other tumor biological features, which may differ with respect to PTX sensitivity. Some molecules, reported to have suppressive effects on tumors, enhance paclitaxel chemosensitivity in breast cancer (19-21) and other cancers $(22,23)$. Therefore, we strongly believe that additional studies to examine the importance of HDRA are needed.

Neoadjuvant chemotherapy is now frequently used for patients with breast cancer. HDRA might be a useful clinical tool for the assessment of breast cancer before surgery. We evaluated HDRA using CNB samples or vacuum-assisted CNB samples from several patients before they underwent surgery or systemic therapy; however, the tissue was insufficient for performing successful HDRAs (data not shown).

The limitations of this study include the small number of patients, especially HER2-positive breast cancer patients, and the short observation period. We also could not choose the type of adjuvant chemotherapy based on the HDRA results. However, we did find a significant association between high PTX IR and outcome. We believe that the results obtained 
Table III. Relationships between clinicopathological factors and inhibition rate of each anticancer agent.

\begin{tabular}{|c|c|c|c|c|c|c|c|c|c|c|c|c|c|c|c|}
\hline \multirow{2}{*}{$\begin{array}{l}\text { Drug agents } \\
\text { Inhibition rate }\end{array}$} & \multicolumn{2}{|c|}{ MMC } & & \multicolumn{2}{|c|}{$5-\mathrm{FU}$} & \multicolumn{4}{|c|}{ ADM } & \multicolumn{2}{|c|}{ CDDP } & \multicolumn{4}{|c|}{ PTX } \\
\hline & $\begin{array}{l}\text { High } \\
(\mathrm{n}=22)\end{array}$ & $\begin{array}{c}\text { Low } \\
(\mathrm{n}=15)\end{array}$ & & $\begin{array}{l}\text { High } \\
(n=18)\end{array}$ & $\begin{array}{c}\text { Low } \\
(\mathrm{n}=19)\end{array}$ & & $\begin{array}{l}\text { High } \\
(\mathrm{n}=17)\end{array}$ & $\begin{array}{l}\text { Low } \\
(\mathrm{n}=16)\end{array}$ & & $\begin{array}{l}\text { High } \\
(\mathrm{n}=18)\end{array}$ & $\begin{array}{c}\text { Low } \\
(\mathrm{n}=12)\end{array}$ & & $\begin{array}{l}\text { High } \\
(\mathrm{n}=16)\end{array}$ & $\begin{array}{l}\text { Low } \\
(\mathrm{n}=10)\end{array}$ & \\
\hline Factors & Number & Number & $p$-Value & Number & Number & $p$-Value & Number & Number & $p$-Value & Number & Number & $p$-Value & Number & Number & $p$-Value \\
\hline Age $($ mean $\pm S D)$ & $64 \pm 3$ & $55 \pm 3$ & 0.061 & $62 \pm 3$ & $60 \pm 3$ & 0.65 & $62 \pm 4$ & $59 \pm 4$ & 0.54 & $60 \pm 3$ & $63 \pm 4$ & 0.67 & $63 \pm 3$ & $57 \pm 4$ & 0.27 \\
\hline \multicolumn{16}{|l|}{ Estrogen receptor } \\
\hline Positive & 9 & 10 & 0.12 & 9 & 10 & 0.87 & 9 & 7 & $0, .73$ & 8 & 6 & 0,77 & 7 & 3 & 0.48 \\
\hline Negative & 13 & 5 & 9 & 9 & 8 & 9 & 10 & 6 & 9 & 7 & & & & & \\
\hline \multicolumn{16}{|l|}{$\begin{array}{l}\text { Progestrone } \\
\text { receptor }\end{array}$} \\
\hline Positive & 8 & 8 & 0.31 & 7 & 9 & 0.6 & 7 & 6 & 0.83 & 7 & 5 & 0.88 & 7 & 1 & 0.07 \\
\hline Negative & 14 & 7 & 11 & 10 & 10 & 10 & 11 & 7 & 9 & 9 & & & & & \\
\hline \multicolumn{16}{|l|}{ HER2 } \\
\hline Positive & 1 & 1 & 0.78 & 1 & 1 & 0.97 & 1 & 1 & 0.97 & 0 & 1 & 0.21 & 0 & 0 & NA \\
\hline Negative & 21 & 14 & 17 & 18 & 16 & 15 & 18 & 11 & 16 & 10 & & & & & \\
\hline \multicolumn{16}{|l|}{ Ki67 } \\
\hline$\leq 20 \%$ & 5 & 3 & 0.84 & 5 & 3 & 0.38 & 5 & 3 & 0.48 & 4 & 3 & 0.86 & 4 & 0 & 0.086 \\
\hline $20 \%<$ & 17 & 12 & 13 & 16 & 12 & 13 & 14 & 9 & 12 & 10 & & & & & \\
\hline \multicolumn{16}{|l|}{$\mathrm{T}$ factors } \\
\hline Tis-2 & 14 & 11 & 0.54 & 11 & 14 & 0.41 & 10 & 12 & 0.32 & 11 & 9 & 0.43 & 9 & 8 & 0.22 \\
\hline T3-4 & 8 & 4 & 7 & 5 & 7 & 4 & 7 & 3 & 7 & 2 & & & & & \\
\hline \multicolumn{16}{|l|}{$\begin{array}{l}\text { Lymph node } \\
\text { metastasis }\end{array}$} \\
\hline Absent & 11 & 5 & 0.32 & 8 & 8 & 0.89 & 9 & 5 & 0.21 & 8 & 4 & 0.54 & 7 & 3 & 0.48 \\
\hline Present & 11 & 10 & 10 & 11 & 8 & 11 & 10 & 8 & 9 & 7 & & & & & \\
\hline \multicolumn{16}{|l|}{ Nuclear Grade } \\
\hline $1-2$ & 10 & 11 & 0.12 & 7 & 14 & 0.018 & 10 & 10 & 0.65 & 10 & 9 & 0.37 & 9 & 6 & 1 \\
\hline 3 & 11 & 4 & 11 & 4 & 7 & 5 & 7 & 3 & 6 & 4 & & & & & \\
\hline \multicolumn{16}{|l|}{$\begin{array}{l}\text { Lymphatic } \\
\text { invasion }\end{array}$} \\
\hline Absent & 6 & 3 & 0.61 & 3 & 6 & 0.29 & 3 & 4 & 0.61 & 3 & 4 & 0.29 & 5 & 1 & 0.21 \\
\hline Present & 16 & 12 & 15 & 13 & 14 & 12 & 15 & 8 & 11 & 9 & & & & & \\
\hline \multicolumn{16}{|l|}{ Venous invasion } \\
\hline Absent & 19 & 14 & 0.5 & 14 & 19 & 0.030 & 14 & 15 & 0.32 & 14 & 12 & 0.079 & 13 & 9 & 0.55 \\
\hline Present & 3 & 1 & 4 & 0 & 3 & 1 & 4 & 0 & 3 & 1 & & & & & \\
\hline \multicolumn{16}{|l|}{ Stage } \\
\hline Stage I-II & 12 & 8 & 0.94 & 10 & 10 & 0.86 & 10 & 8 & 0.61 & 10 & 6 & 0.77 & 8 & 5 & 1 \\
\hline Stage III-IV & 10 & 7 & 8 & 9 & 7 & 8 & 8 & 6 & 8 & 5 & & & & & \\
\hline Reccurence & 5 & 2 & 0.43 & 4 & 3 & 0.56 & 4 & 3 & 0.1 & 4 & 2 & 0.65 & 2 & 4 & 0.13 \\
\hline Non reccurrent & 16 & 13 & 13 & 16 & 13 & 12 & 13 & 10 & 13 & 6 & & & & & \\
\hline Cancer death & 2 & 0 & 0.23 & 1 & 1 & 0.97 & 2 & 0 & 0.16 & 1 & 1 & 0.77 & 1 & 1 & 0.73 \\
\hline Alive & 20 & 15 & 17 & 18 & 15 & 16 & 17 & 11 & 15 & 9 & & & & & \\
\hline
\end{tabular}

SD, Standard deviation; MMC, mitomycin C; 5-FU, 5-fluorouracil; ADM, doxorubicin hydrochloride; CDDP, cisplatin; PTX, paclitaxel.

from patients who received standard adjuvant chemotherapy are noteworthy; however, a larger study with a longer observation period is considered necessary.

\section{References}

1 Anampa J, Makower D and Sparano JA: Progress in adjuvant chemotherapy for breast cancer: an overview. BMC Med 13: 195, 2015. DOI 10. 1186/s12916-015-0439-8
2 Muss HB, Thor AD, Berry DA, Kute T, Liu ET, Koerner F, Cirrincione CT, Budman DR, Wood WC, Barcos $\mathrm{M}$ and Henderson IC: c-erbB-2 expression and response to adjuvant therapy in women with node-positive early breast cancer. N Engl J Med 330: 1260-1266, 1994.

3 Furukawa T, Kubota T, Watanabe M, Takahara T, Yamaguchi H, Takeuchi T, Kase S, Kodaira S, Ishibiki K, Kitajima M and Hoffman RM: High in vitro-in vivo correlation of drug response using sponge-gel-supported three-dimensional histoculture and the MTT end point. Int J Cancer 51(3): 489-498, 1992. 
4 Furukawa T, Kubota T and Hoffman RM: Clinical applications of the histoculture drug response assay. Clin Cancer Res 1(3): 305-311, 1995.

5 Kubota T1, Sasano N, Abe O, Nakao I, Kawamura E, Saito T, Endo M, Kimura K, Demura H, Sasano H, Nagura H, Ogawa N, Hoffman RM and the Chemosensitivity Study Group for the Histoculture Drug-Response Assay: Potential of the histoculture drug-response assay to contribute to cancer patient survival. Clin Cancer Res 1(12): 1537-1543, 1995.

6 Tanino H, Oura S, Hoffman RM, Kubota T, Furukawa T, Arimoto J, Yoshimasu T, Hirai I, Bessho T, Suzuma T, Sakurai $\mathrm{T}$ and Naito $\mathrm{Y}$ : Acquisition of multidrug resistance in recurrent breast cancer demonstrated by the histoculture drug response assay. Anticancer Res 21(6A): 4083-4086, 2001.

7 Fujita Y, Hiramatsu M, Kawai M, Nishimura H, Miyamoto A and Tanigawa $\mathrm{N}$ : Histoculture drug response assay predicts the postoperative prognosis of patients with esophageal cancer. Oncol Rep 21(2): 499-505, 2009.

8 Lee SW1, Kim YM, Kim MB, Kim DY, Kim JH, Nam JH and Kim YT: Chemosensitivity of uterine cervical cancer demonstrated by the histoculture drug response assay. Tohoku J Exp Med 219(4): 277-282, 2009.

9 Gnant M, Harbeck N and Thomssen C: St. Gallen 2011: Summary of the Consencus Discussion. Breast Care 6: 136-141, 2011.

10 National Comprehensive Cancer Network: NCCN clinical practice guidelines in oncology ( $\mathrm{NCCN}$ guidelines) Breast Cancer, 2015.

11 Tanino H, Kubota T, Oura S, Yamamichi N, Suzuma T, Yoshimasu T, Yoshimura G, Maebeya S, Sakurai T and Naito Y: Histoculture drug response assay for identification of active agents in multidrug-resistant recurrent breast cancer. Jpn J Breast Cancer 13(4): 719-725, 1998

12 Coates AS, Winer EP, Goldhirsch A, Gelber RD, Gnant M, Piccart-Gebhart M, Thürlimann B and Senn HJ; Panel Members: -Tailoring therapies-improving the management of early breast cancer: St Gallen International Expert Consensus on the Primary Therapy of Early Breast Cancer 2015. Ann Oncol 26(8): 15331546, 2015.

13 Osako T, Horii R, Matsuura M, Domoto K, Ide Y, Miyagi Y, Takahashi S, Ito Y, Iwase T and Akiyama F: High-grade breast cancers include both highly sensitive and highly resistant subsets to cytotoxic chemotherapy. J Cancer Res Clin Oncol 136(9): 1431-1438, 2010

14 Kim KY, Chung BW, Yang I, Kim MB and Hoffman RM: Independence of cytotoxic drug sensitivity profiles and receptor subtype of invasive ductal breast carcinoma demonstrated by the histoculture drug response assay (HDRA). Anticancer Res 34(12): 7197-7201, 2014.
15 Yoshimasu T, Oura S, Hirai I, Tamaki T, Kokawa Y, Ota F, Nakamura R, Shimizu Y, Kawago M, Hirai Y, Naito K, Kiyoi M, Tanino H, Okamura $\mathrm{Y}$ and Furukawa T: In vitro evaluation of dose-response curve for paclitaxel in breast cancer. Breast Cancer 14(4): 401-405, 2007.

16 Nishimura R, Osako T, Okumura Y, Hayashi M and Arima N: Clinical significance of Ki-67 in neoadjuvant chemotherapy for primary breast cancer as a predictor for chemosensitivity and for prognosis. Breast Cancer 17: 269-275, 2010.

17 Loibl S, Jackisch C, Lederer B, Untch M, Paepke S, Kummel S, Schneeweiss A, Huober J, Hilfrich J, Hanusch C, Gerber B, Editmann H, Denkert C, Costa SD, Blohmer JU, Nekljudova V, Mehta K and Minckwitz GV: Outcome after neoadjuvant chemotherapy in young breast cancer patients: a pooled analysis of individual patient data from eight prospectively randomized controlled trials. Breast Cancer Res Treat 152: 377-387, 2015.

18 Houssami N, Macaskill P, Minckwitz GV, Marinovich M and Mamounas E: Meta-analysis of the association of breast cancer subtype and pathologic complete response to neoadjuvant chemotherapy. Eur J Cancer 48: 3342-3354, 2012.

19 Liu X, Tang H, Chen J, Song C, Yang L, Liu P, Wang N, Xie X, Lin $\mathrm{X}$ and Xie X: MicroRNA-101 inhibits cell progression and increases paclitaxel sensitivity by suppressing MCL-1 expression in human triple-negative breast cancer. Oncotarget 6(24): 2007020083, 2015.

20 Kang L, Mao J, Tao Y, Song B, Ma W, Lu Y, Zhao L, Li J, Yang $\mathrm{B}$ and Li L: MicroRNA-34a suppresses the breast cancer stem cell-like characteristics by downregulating Notch1 pathway. Cancer Sci 106(6): 700-708, 2015.

21 Xue J, Chi Y, Chen Y, Huang S, Ye X, Niu J, Wang W, Pfeffer LM, Shao ZM, Wu ZH and Wu J: MiRNA-621 sensitizes breast cancer to chemotherapy by suppressing FBXO11 and enhances p53 activity. Oncogene 35: 448-458, 2016.

22 Cao L, Chen S, Zhang C, Chen C, Lu N, Jiang Y, Cai Y, Yin Y and $\mathrm{Xu}$ J: ING4 enhances paclitaxel's effect on colorectal growth in vitro and in vivo. Int J Clin Exp Pathol 8(3): 29192927, 2015

23 Liu R, Liu X, Zheng Y, Gu J, Xiong S, Jiang P, Huang E, Yang Y, Ge D and Chu Y: MicroRNA-7 sensitizes non-small cell lung cancer cells to paclitaxel. Oncol Lett 8: 2193-2200, 2014.

24 Greene FL, Breast tumours. In: Sobin LH, Gospodarowicz MK, Wittekind $\mathrm{C}$ and editors. TNM classification of malignant tumours. 7th ed. Oxford, Wiley-Blackwell., pp 181-193, 2009.

Received June 20, 2016

Revised July 7, 2016

Accepted July 11, 2016 